Article

\title{
Using Landsat OLI and Random Forest to Assess Grassland Degradation with Aboveground Net Primary Production and Electrical Conductivity Data
}

\author{
Hao Yu ${ }^{1,2}{ }^{\oplus}$, Lei Wang ${ }^{3}{ }^{\oplus}$, Zongming Wang ${ }^{2}$, Chunying Ren ${ }^{2, *}$ and Bai Zhang ${ }^{2}$ \\ 1 School of Geomatics and Prospecting Engineering, Jilin Jianzhu University, Changchun 130118, China; \\ yuhao@jlju.edu.cn or xiaoxiaoyupiu@163.com \\ 2 Key Laboratory of Wetland Ecology and Environment, Northeast Institute of Geography and Agroecology, \\ Chinese Academy of Sciences, Changchun 130102, China; zongmingwang@iga.ac.cn (Z.W.); \\ zhangbai@neigae.ac.cn (B.Z.) \\ 3 Department of Geography and Anthropology, Louisiana State University, Baton Rouge, LA 70803, USA; \\ leiwang@lsu.edu \\ * Correspondence: renchy@iga.ac.cn; Tel.: +86-431-8554-2297
}

Received: 4 October 2019; Accepted: 6 November 2019; Published: 12 November 2019

\begin{abstract}
Grassland coverage, aboveground net primary production (ANPP), and species composition are used as indicators of grassland degradation. However, soil salinization deficiency, which is also a factor of grassland degradation, is rarely used in grassland degradation assessment in semiarid regions. We assessed grassland degradation by its quality, quantity, and spatial pattern over semiarid west Jilin, China. Considering soil salinization in west Jilin, electrical conductivity (EC) is used as an index with ANPP to assess grassland degradation. First, the spatial distribution of the grassland was measured with information mined from multi-temporal remote sensing images using an object-based image analysis combined with classification and decision tree methods. Second, with 166 field samples, we utilized the random forest (RF) algorithm as the variable selection and regression method for predicting EC and ANPP. Finally, we created a new grassland degradation model (GDM) based on ANPP and EC. The results showed the $\mathrm{R}^{2}(0.91)$ and RMSE $(0.057 \mathrm{mS} / \mathrm{cm})$ of the EC model were generally highest and lowest when the $n$ tree was 400 ; the ANPP model was optimal $\left(R^{2}=0.85\right.$ and RMSE $=15.81 \mathrm{gC} / \mathrm{m}^{2}$ ) when the ntree was 600 . Grassland area of west Jilin was $609.67 \times 10^{3}$ ha in 2017 , there were $373.79 \times 10^{3}$ ha of degraded grassland, with $210.47 \times 10^{3}$ ha being intensively degraded. This paper surpasses past limitations of excessive reliance on vegetation index to construct a grassland degradation model which considers the characteristics of the study area and soil salinity. The results confirm the positive influence of the ecological conservation projects sponsored by the government. The research outcome could offer supporting data for decision making to help alleviate grassland degradation and promote the rehabilitation of grassland vegetation.
\end{abstract}

Keywords: remote sensing; aboveground net primary productivity (ANPP); soil salinity; grassland degradation model (GDM); random forest (RF); principle component analysis (PCA)

\section{Introduction}

Grasslands make entire ecosystems more resilient to environmental changes by preventing soil erosion and regularizing water regimes, particularly in arid/semiarid regions [1,2]. Area and spatial distribution information of grasslands is important for understanding plant, animal, and bird species survival [3]. Grasslands also play a vital role in sustaining human lives [4]. Grassland degradation is the process of retrograde succession and productivity decline of the grassland ecosystem under unreasonable utilization (overgrazing and irrational reclaiming) and unusual natural processes 
(drought, wind sand, water erosion, saline-alkali, waterlogging etc.) [5,6]. The main manifestations are the height, coverage, yield and quality of grassland vegetation, the deterioration of soil habitat, and the decline of production capacity and ecological function [7]. In the past several decades, the degradation of grassland caused not only the decline of productivity of grassland itself, but also the deterioration of ecological environment and the threat to human survival and development. In recent decades, grassland degradation has become a severe global environmental problem (e.g., endangering regional ecosystem services and functions) [8-10]. At present, about $90 \%$ of grasslands in China undergo degradation and $34 \%$ of rangelands are moderately to severely degraded [11,12]. Human activities can completely convert grasslands to other land functions [13], which could turn fertile soil into barren lands (e.g., saline-alkali land, sand) that can no longer yield products [14-16]. Measuring the degradation of grassland ecosystems is an urgent issue for both the government and local communities, especially for semiarid and arid regions of China where ecosystems are more fragile.

Grassland degradation is conventionally studied through field investigation, but this method is time-consuming and costly in large-scale research. Remote sensing offers numerous technologies to monitor grassland degradation [17-19]. Most research on grassland degradation has been carried out by measuring changes of grassland area [20,21], aboveground vegetation condition [22,23], and other characteristics of grasslands [24]. The assessment methods of grassland degradation can be divided into two categories: Visual classification and degraded index inversion. The former classifies the levels of grassland degradation according to the characteristics of imagery, which has a higher demand for classification experts in the professional aspect and is time-consuming and costly compared with the latter. With the emergence of massive remote sensing data, the latter is more widely used for grassland degradation assessment. Zhang et al. used Normalized Differential Vegetation Index (NDVI) data (8 km spatial resolution) to evaluate grassland degradation over the Mongolia Plateau [25]. $\mathrm{Li}$ et al. estimated grassland aboveground biomass using multi-temporal MODIS data (250 $\mathrm{m}$ spatial resolution) in the West Songnen Plain, China [22]. Tarantino et al. detected the changes in semi-natural grasslands by cross correlation analysis with WorldView-2 images and Landsat 8 data [26]. Wang et al. monitored grassland degradation through effective spectral feature parametrization methods exactly distinguished the constructive species and degraded indicators using hyperspectral remote sensing data [27]. Liu et al. assessed the grassland degradation from Landsat TM image in conjunction with grass cover and proportion of unpalatable grasses (PUG) [24]. In review of previous researches, although the low spatial resolution sensors have high temporal resolution, which enables a good overview of grassland dynamics, they are not suitable for obtaining the details of area change and monitoring degraded levels at regional scale [28]. High spatial resolution imagery has affluent detail information and prominent texture information of terrestrial object which compensates for the spatial limitation, but it could not be widely used for spatial assessment of grassland degradation at large scale due to its small coverage and expensive cost [29]. Landsat 8 Operational Land Imager (OLI) has a spatial resolution of $30 \mathrm{~m}$. In addition, there is a panchromatic band with a resolution of $15 \mathrm{~m}$, which could fulfill the demands for monitoring grassland degradation. Therefore, the medium spatial resolution was extensively applied for the evaluation of grassland degradation [23,30,31].

In the selection of degradation indicators, previous studies evaluated the degraded level by vegetation cover, vegetation biomass, aboveground net primary production (ANPP), PUG and grassland species. Aboveground net primary production is the energy value that producers can use for growth, development, and reproduction, and it is also the material basis for the survival and reproduction of other biological members in the ecosystem. Moreover, ANPP is a parameter that can reflect environment changes because it is sensitive to biological and abiotic factors [32]. Variability in ANPP has been used as an indicator to measure the loss of ecosystem function due to grassland degradation in several studies $[33,34]$. These studies took full account of the grassland situation above the ground, but did not consider the soil circumstance of grassland. Moreover, grassland salinization, a common phenomenon due to the buildup of salts in soil, is the primary form of grassland degradation in arid, semi-arid, and dry sub-humid areas $[35,36]$. West Jilin Province of China is a typical semiarid 
region that lies between saline-alkali land and wind-blown sand land. The low-lying terrain and poor drainage blocked the waterways from releasing salts, consequently causing soil salinization and grassland degradation $[37,38]$. The research shows that the area of soil salinization accounts for $34 \%$ of West Jilin Province. About $77 \%$ of grassland areas were salt-affected [39]. The grasslands in this area used to be good pasture with high yield and good grass quality, but due to uncontrolled exploitation and utilization of land resources, the vegetation cover has been seriously degraded in recent years. Previous research established that soil salinization was a factor in grassland degradation in semiarid and arid regions [37,40]. This has been accompanied by serious salinization; the grassland degradation has also been enhancing itself through a negative feedback mechanism caused by land cover change and soil salinization $[37,41]$. Yu et al. (2018) reported that grassland was the most severely affected by salinity among all vegetation land covers in West Jilin Province. Other authors studied salinization characteristics of saline and alkali grassland soils in semiarid regions and analyzed the differences in grassland patterns with different salinity and alkali levels [41]. The growth of vegetation is directly affected by the soil properties. It is necessary to establish an evaluation system of grassland degradation based on grassland biomass and soil salinity in semiarid regions and then analyze the spatial distribution of degraded grassland combined with auxiliary data in the study area $[42,43]$. In previous studies, more attention has been paid to aboveground biomass, plant coverage, and species of vegetation than soil properties in estimating grassland degradation. Therefore, this paper aims to establish a new grassland degradation model (GDM), designed for semiarid regions and based on the spatial distribution of ANPP and soil salinity to grassland degradation measured from satellite imagery.

Random forest (RF) has been widely used in vegetation biomass and soil parameter estimation in recent years [44,45]. The RF is a popular ensemble learning method that can be used to establish predictive models for both classification and regression problems using the random uncorrelated decision tree [46]. Compared with general regression analysis, RF has very fast speed of processing, and it performs well in dealing with big data. The RF does not need to worry about the multivariate collinearity problem. RF method is not sensitive to noise in training samples. Therefore, the accuracy of models could be much higher compared with other machine learning and the traditional statistical regressions [47]. Here, the inversion models of ANPP and electrical conductivity (EC) were established by the RF obtaining the relationship between remote sensing imagery' spectral information and field samplings.

This research has the following objectives: (1) measure the grassland extent and their spatial distribution over west Jilin Province in 2017; (2) formulate the relationships between reflectance bands, spectral indices, and field measurements of ANPP and EC using RF; and (3) and establish the grassland degradation model by principle component analysis (PCA) using the predicted ANPP and EC. We expect that the outcome of this research could offer a remote-sensing-based grassland degradation monitoring methodology for long-term land resource management in semiarid regions.

\section{Materials and Methods}

\subsection{Materials}

\subsubsection{Study Area Descriptions}

The west Jilin Province $\left(43^{\circ} 59^{\prime} \sim 46^{\circ} 18^{\prime} \mathrm{N}, 121^{\circ} 38^{\prime} \sim 126^{\circ} 11^{\prime} \mathrm{E}\right)$, one of the most serious saline-alkali areas in the world [48], is located in the southern Songnen Plains in northeast China. The elevation of the study area ranges from 100-200 $\mathrm{m}$ above sea level [49]. The area is influenced by temperate, semi-arid continental monsoon climate. The mean annual precipitation is about $411 \mathrm{~mm}$, which increases gradually from west to east. The mean annual evaporation is about three times as much as precipitation and increases from east to west. High evaporation and low precipitation are major factors for soil salinization over west Jilin Province [39,50]. Average winter temperature is $-16{ }^{\circ} \mathrm{C}$ and summer is $23^{\circ} \mathrm{C}$. Winds are generally moderate year round, averaging $3-6 \mathrm{~m} / \mathrm{s}[51,52]$. 
Grassland is the most widely distributed land cover type except cropland in this area. The species of grass are Leymus chinensis, Phragmites australis, Leymus secalinus, Spodiopogon sibiricus, Cleistogenes polyphylla, Chloris virgate, and Iris lactea var. chinensis. During past decades, the proportion of Leymus chinensis decreased, but the proportion of unpalatable grassland increased with the increasing prominence of ecological environment problems. The soils are Chernozem (Haplic Chernozem, FAO, Rome, Italy), meadow soil (EutricVertisol, FAO, Rome, Italy), aeolian soil (Arenosol, FAO, Rome, Italy), Solonetz (Solonetz, FAO, Rome, Italy), and Chestnut soil (Haplic Kastanozem, FAO, Rome, Italy). The widespread fragmented, scar-like saline lands are part of the grassland. In the past decades, about $20 \%$ of the grasslands in the west Jilin Province have been reclaimed as farmland due to population growth and increased food demand; additionally, some regions of grasslands were depleted by overgrazing [53]. These land uses all led to the rapid reduction in the area of natural steppes [54]. The phenomenon of grassland degradation is noticeable, seriously restricting the development of both natural ecology and social economy. Figure 1 shows the location of the study area.

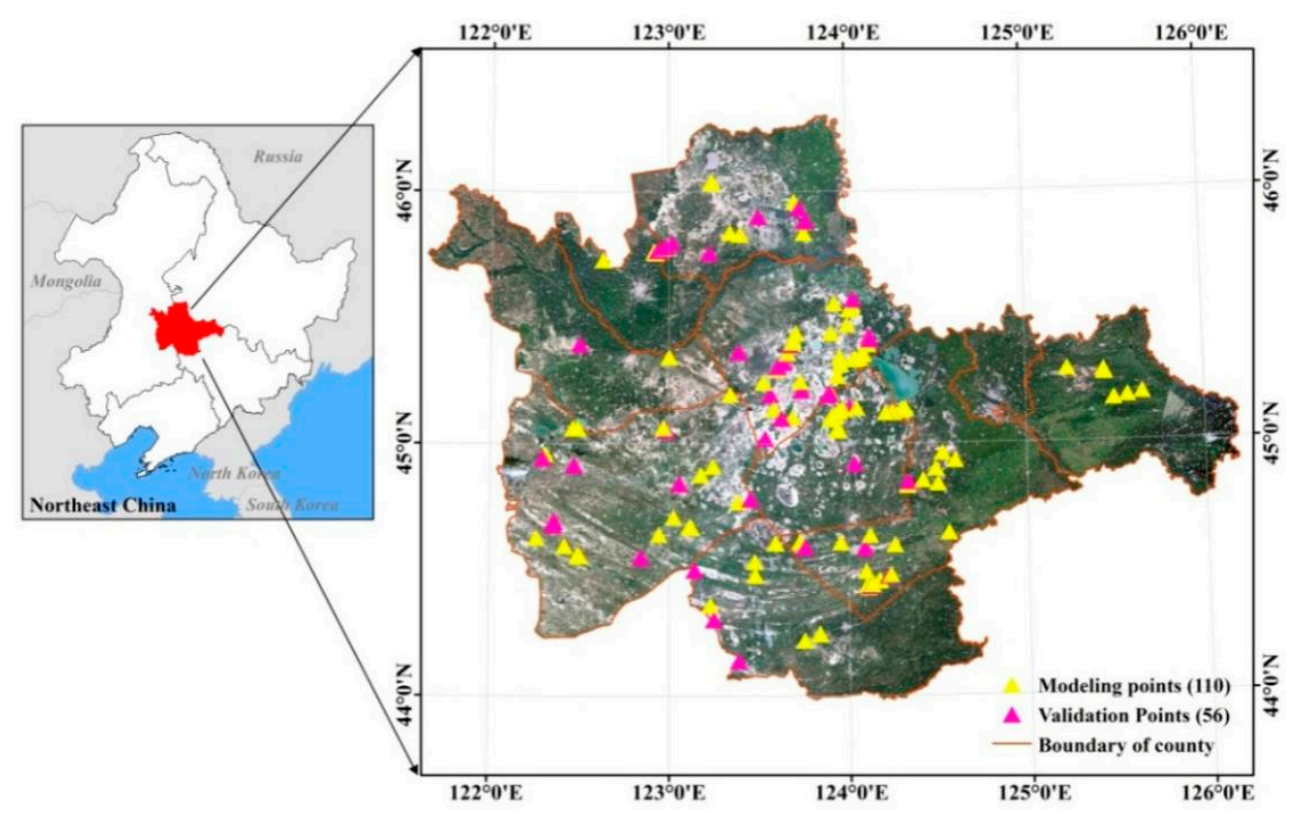

Figure 1. Locations of study areas and the samplings' locations mentioned in this paper, with true color composite image of Landsat Operational Land Imager (OLI) in 2016 and 2017.

\subsubsection{Remote Sensing and Pre-Processing}

We used a total of six scenes from Landsat 8 OLI (https://www.usgs.gov/) and two Sentinel-2A scenes (https://scihub.copernicus.eu/) from the year 2017. The sentinel-2A scenes were only used to verify the accuracy of land cover type classification in 2017. Most of the image data for this study is cloud-free and acquired during similar seasons (August-September). The spatial resolution is $30 \mathrm{~m}$, which is sufficient for grassland and other land use analysis [49]. Geo-rectification, atmospheric correction, and radiometric calibration were applied to each image prior to interpretation to correct additive and multiplicative atmospheric effects; band reflection and spectral indices could be calculated after processing [55]. In order to better understand the relationship between spectral information and measured data in the field, we selected eight spectral indices, which include Normalized Differential Vegetation Index [56,57], Enhanced Vegetation Index (EVI) [58], Soil Adjusted Vegetation Index (SAVI) [59], and Salinity Index (SIs) [60,61]. All spectral indices are listed in Table 1. 
Table 1. The expressions of spectral indices.

\begin{tabular}{ccc}
\hline Spectral Index & Expression & Full Name \\
\hline NDVI & $(\mathrm{NIR}-$ Red $) /(\mathrm{NIR}+$ Red $)$ & Normalized Difference Vegetation Index \\
DVI & NIR - Red & Different Vegetation Index \\
EVI & NIR/Red & Enhanced Vegetation Index \\
SAVI & $(\mathrm{NIR}-$ Red $) /(\mathrm{NIR}+\mathrm{Red}+0.5) \times 1.5$ & Soil Adjusted Vegetation Index \\
SI & $\sqrt{\mathrm{Green} \times \text { Red }}$ & Salinity Index \\
SI2 & $\sqrt{\mathrm{Green}^{2}+\operatorname{Red}^{2}+\mathrm{NIR}^{2}}$ & Salinity Index2 \\
SI3 & $\sqrt{\mathrm{Green}^{2}+\mathrm{Red}^{2}}$ & Salinity Index3 \\
SI4 & SWIR1/NIR & Salinity Index4 \\
\hline
\end{tabular}

\subsubsection{Field Data and Samplings' Processing}

Soil and grassland biomass samples were collected from 170 sampling sites located in grassland with different status. Three $0.5 \mathrm{~m}^{2}$ plots at peak biomass were selected in each area (10-21 August 2016 and 8-19 August 2017); green and recently dead grass material at the soil surface was clipped and placed in paper bags [62]. After obtaining the grassland biomass, soil samples were collected from the $0-5 \mathrm{~cm}$ layer under the corresponding grassland. All grassland samples were dried for at least $48 \mathrm{~h}$ at $65^{\circ} \mathrm{C}$ and then weighed. In order to more effectively compare with previous studies, grassland biomass (g) units are expressed in the form of carbon ( $\mathrm{gC}$ ) [35,63]; biomass and the conversion coefficient $(0.45)$ were used to measure ANPP according to Piao et al. (2002) and Chen et al. (2008). The expression is as follows:

$$
B_{g}=\frac{N P P}{S_{b n}\left(1+S_{u g}\right)}
$$

$B_{g}$ represents the hay yield of grassland per unit area $\left(\mathrm{g} / \mathrm{m}^{2}\right) ; S_{b n}$ represents the conversion coefficient, the value is 0.45 and the unit is $\mathrm{g} / \mathrm{gC}$; and $S_{u g}$ represents the ratio coefficient of biomass between the aboveground and underground parts of the grassland. In this study, we only analyze the ANPP; therefore, the value was 0.

The EC was obtained by soil laboratory tests. First, each soil sample was crushed by pestle after air-drying. Second, we prepared a 1:5 soil:water suspension by passing $10 \mathrm{~g}$ soil through a $2 \mathrm{~mm}$ sieve. The suspension was mechanically shaken at $15 \mathrm{rpm}$ for $1 \mathrm{~h}$ to dissolve soluble salts. Finally, we tested the electrical conductivity using LEICI DDS-307A meter [16,64]. Results of the test showed that four data points' values were aberrant, so we deleted the data from these four sampling points when establishing the inversion models. Currently, 166 valid sampling points have been divided into two parts which included a training dataset $(n=116)$ and a validation dataset $(n=50)$.

Auxiliary data was used to support the interpretation and result analysis. Digital Elevation Model (DEM, resolution $30 \mathrm{~m}$ ) data was used for classification and geo-rectified. The reference/validation sites for classification of land cover in 2017 were obtained from field survey, random extraction from Sentinel-2A, and from Google Earth.

\subsection{Methods}

\subsubsection{Object-Based Image Analysis (OBIA) and Decision Tree}

Object-Based Image Analysis (OBIA) divides the image into non-overlapping objects; there is no gap between objects, which is in accord with the topological relationship. OBIA involves pixels being grouped into objects based on either spectral similarity of images or an external variable such as ownership, soil type, or geological altitude [65]. An image object provides richer information, including spectral information, texture, and geometric features, as well as the relationship between different objects, such as distance [66]. There are three parameters that determine the segmentation effect: Scale, shape, and compactness $[67,68]$. The optimal scale of segmentation is determined by multiple 
experiments and comparing effects. In this paper, the scale set to 100 for Landsat OLI could satisfy our research requirements; the value of shape and compactness parameter was 0.3 and 0.6 , respectively.

Decision tree (DT) is the process of using informative rule sets to realize classification [69]. The rules are easy to understand and the classification process is also in line with the cognitive process of human beings [70]. The most distinctive characteristic of a decision tree is the flexibility to use multi-source data such as vector data, different spatial resolution images, and other auxiliary data (geographical, meteorological, and economic). Moreover, the decision tree could accept auxiliary data as input data with incomplete records [71]. Therefore, interpretation of grassland was completed by OBIA and DT. It is more difficult to extract grassland information compared with other vegetation types such as farmland and forestland. Thus, the distribution of grassland was extracted in two steps: (1) excluding the easily identifiable land cover types (non-vegetation, farmland, and forestland); (2) confirming the edge of the grassland according to measured data and spectral information (Figure 2).

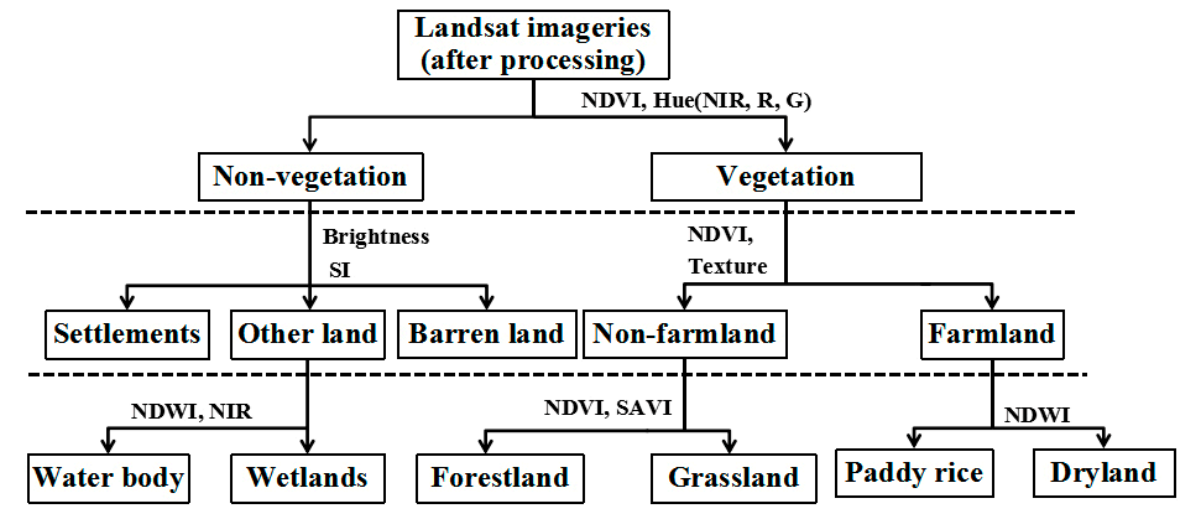

Figure 2. Decision-tree models for grassland classification of the west Jilin Province in 2017. (The threshold of each rule set varied with images. NIR is near-infrared band, R is red band, $\mathrm{G}$ is green band. NDWI is the Normalized Difference Water Index, calculated from G and NIR bands).

\subsubsection{Random Forest Regression}

$\mathrm{RF}$ is a powerful machine learning classifier, which has good anti-noise ability for regression performance yet has not been thoroughly evaluated in remote sensing [72,73]. RF is composed of multiple decision trees, which can be predicted by combining a series of decisions of basic models [74] improving the prediction accuracy by the average value of multiple classification decision trees on each subsample [75]. RF uses a random input subset or variables in node partition instead of the best variables, aims to reduce the generalization error, and achieves the highest accuracy [76]. Ultimately, RF algorithm has the prominent advantages of being nonparametric, prediction results with high accuracy, and the ability to measure the importance of variables compared to linear regression algorithms $[73,76]$.

The fourteen variables used for grassland degradation assessment comprise eight spectral indexes and six spectral bands. The variables for predicting ANPP and EC were screened by RF, which excludes variables with a lower score of importance. R software package "randomForest" was used to implement inversion of ANPP and EC, and the inversion models were confirmed by three parameters: ntree, $m$ try, and nodesize $[44,45]$. The nodesize value defaulted to one, which represents the minimal size of the terminal nodes of the tree; ntree specifies the number of decision trees contained in a random forest; $m$ try specifies the number of variables in the node for the binary tree. Figure 3 illustrates how to establish the relationship between remote sensing imagery and field measurement to obtain the inversion models of soil salinity (EC) and ANPP inverse using RF.

The $n$ tree boot samples (containing approximately one third of the elements of original dataset) were randomly extracted with playback from the original dataset; the unselected samplings comprise out-of-bag (OOB) data for testing. The prediction accuracy of each decision tree is determined by the average OOB [77]. The importance score can test the variables importance, which is calculated by the 
increase percent in mean square error through permuting each variable when others are not changed. Finally, the accuracy of RF is measured by the coefficient of determination $\left(R^{2}\right)$ and root mean square error (RMSE). In addition, model uncertainty should be carefully presented as the model output [78].

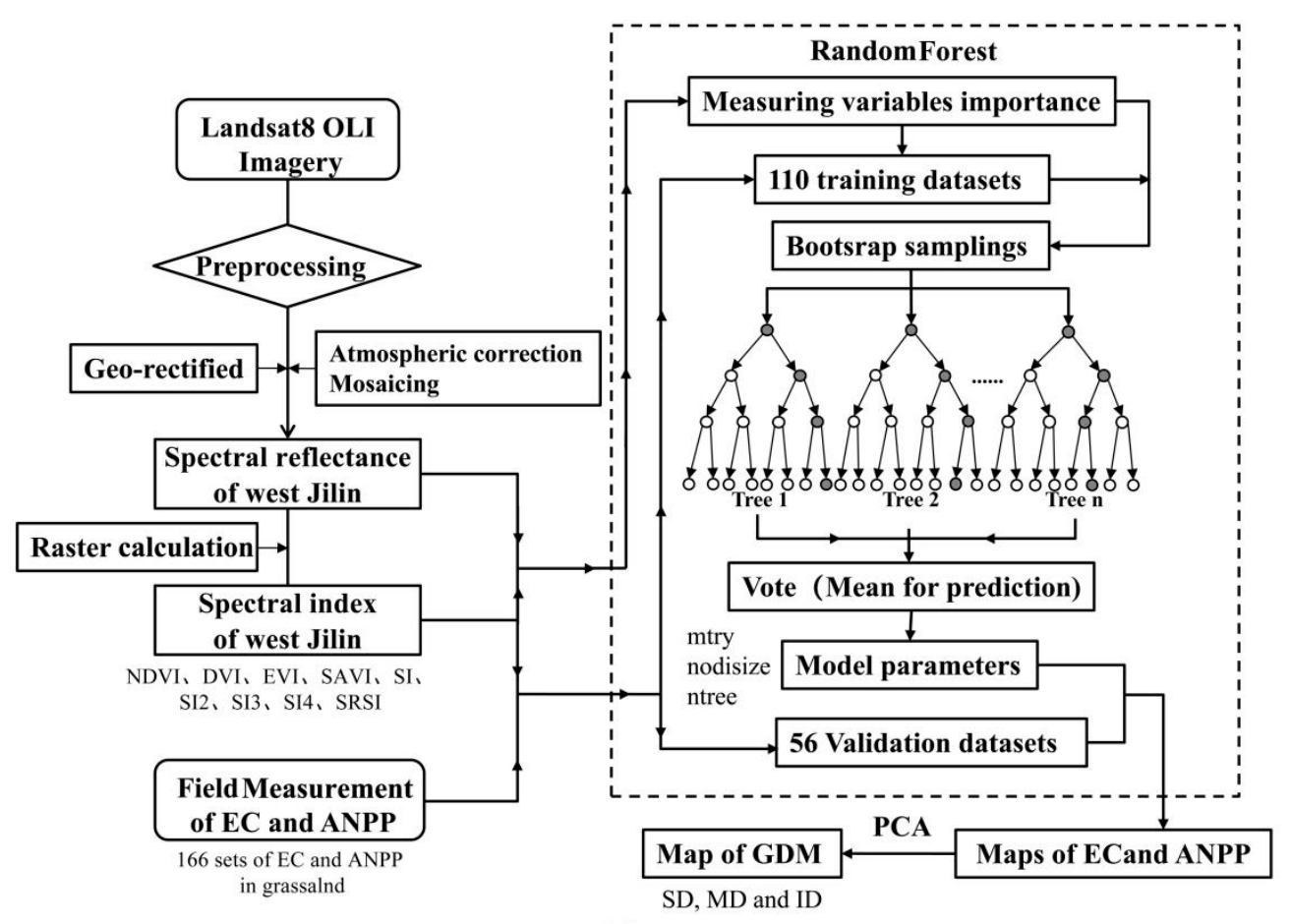

Figure 3. The flow-process diagram of random forest (RF) to assess grassland degradation parameters using remote sensing images and field measurements in Semiarid West Jilin, China (SD is slightly degraded, MD is moderately degraded, and ID is intensively degraded).

In our study, we not only verified the overall accuracy of the models, but also analyzed the spatial distribution of the uncertainty of the inversion models. The spatial distribution of uncertainty provides a map of the uncertainty rather than an RMSE and can therefore help understand and improve the model from a geographical aspect. The flowchart is showed in Figure 4 and the specific steps are as follows:

(1) Create a fishnet structure covering the region of grassland with a cell size of $2500 \mathrm{~m}$ and then extract the center point of each cell to represent the locations (Figure 4a).

(2) Assign each center point an RMSE value that is calculated based on values of sample locations. The value of the center points is the average RMSE value of multiple sampling points; the sampling points are close to the center points with a control distance (Figure $4 \mathrm{~b}$ ), which is set as $3000 \mathrm{~m}$ based on the area of the study area and density of sampling points in this study.

(3) Move window to the next point until all center points are processed (Figure 4c).

(4) Delete points with null value and generate the spatial uncertainty of the model by the spatial analysis tools. 


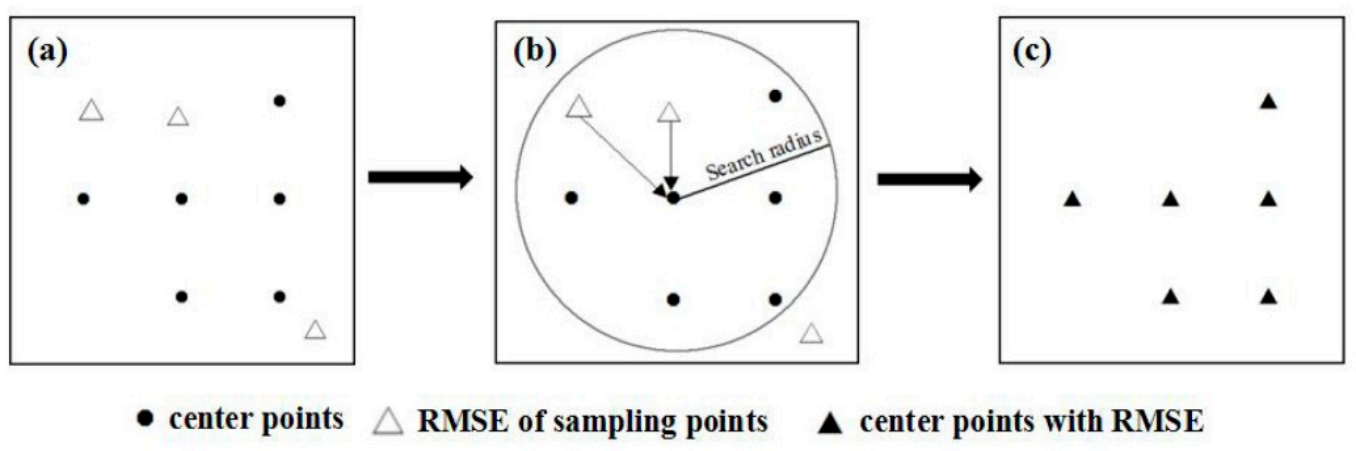

Figure 4. The schematic diagram of spatial uncertainty evaluation method. (a) extract the center points by creating a fishnet structure covering the region of grassland; (b) assign the sampling points' value by calculating the average value of all points within a certain distance; (c) complete calculation of all points in window and go to next window until finish all points.

\subsubsection{Grassland Degradation Model from the Principal Component Analysis}

Both ANPP and EC are important indicators of grassland degradation. However, the grassland degradation model must use their weighted combination, where the weights cannot be determined from empirical studies due to the lack of reference. If the weights are determined arbitrarily, it is difficult to justify or make the model generalizable. Herein, the weights of these two parameters were calculated by principal component analysis.

The principle of PCA is to attempt to recombine the original variables into a new group of independent comprehensive variables by orthogonal transformation. The transformed variables are called principal components, each one being described by an eigenvector and its eigenvalue of the covariance matrix of the input variables [79]. The principle components are combined by mutually uncorrelated variables with maximal variance. The intuitive purpose of PCA is to reduce the dimension of redundant data features, while retaining the most important part of the data features, so that the main components can maintain the integrity of all the data information. The GDM value will be the first principal component calculated by PCA method. The formula expression is as follows:

$$
\mathrm{F}=\mathrm{AU}
$$

$\mathbf{X}$ is a matric with $n$ rows and $m$ columns. A is an adjusted data matric, which is equal to experiment value $(\mathbf{X})$ minus the average of each column, $\mathbf{F}$ represents the new variables which are calculated by PCA, and $\mathbf{U}$ is a matric of the eigenvalue vectors which is calculated through $\mathbf{A}^{\prime}$ s covariance.

$$
\mathbf{F}=\mathbf{A} \mathbf{U}=\left[\begin{array}{cccc}
a_{11} & a_{12} & \cdots & a_{1 k} \\
a_{21} & a_{21} & \cdots & a_{2 k} \\
\vdots & & \vdots & \\
a_{n 1} & a_{n 2} & \cdots & a_{n k}
\end{array}\right]\left[\begin{array}{cccc}
\lambda_{11} & \lambda_{12} & \cdots & \lambda_{1 m} \\
\lambda_{21} & \lambda_{22} & \cdots & \lambda_{2 m} \\
\vdots & & \vdots & \\
\lambda_{n 1} & \lambda_{n 2} & \cdots & \lambda_{n m}
\end{array}\right]=\left[\begin{array}{cccc}
v_{11} & v_{12} & \cdots & v_{1 k} \\
v_{21} & v_{22} & \cdots & v_{2 k} \\
\vdots & & \vdots & \\
v_{m 1} & v_{m 2} & \cdots & v_{m k}
\end{array}\right]
$$

C is the matrix of parameters' coefficients which were calculated by eigenvalue and eigenvalue vector. The expression is as follows:

$$
\mathbf{C}_{i}=\mathbf{U}_{i} \sqrt{\text { Eigenvalue }_{i}}
$$

$i$ is the number of principle components, and $\mathbf{C}_{i}$ is the coefficient matrix of the parameters to the $i$ principal component of analysis result. In this part, input data were the spatial distribution of ANPP and EC, which were calculated by RF method. The first component was the output result through orthogonal transformation. 


\section{Results}

\subsection{Random Forest Modeling for EC and ANPP}

RF has the ability to rank the importance of variables before predicting ANPP and EC. Using the RF method, we ranked the importance score of all variables and selected the variables with higher scores as the variables for establishing the inversion models [45]. We measured variables of importance for estimating ANPP and EC. Figure 5 shows the band Green and SI were more noticeable for the EC model, and the band Coastal, NDVI, and SAVI had more importance than other predicted variables for establishing the ANPP model. Taking this into consideration, we chose bands Green, Red, Blue, NIR and spectral indexes SI and EVI as the predicted variables for inverse EC model and bands Coastal, SWIR, Red, Blue and spectral indexes SAVI and NDVI as the predicted variables for establishing the ANPP model.

The inversion results of ANPP and EC were determined by three parameters: nodesize, ntree, and mtry [80]. Generally, mtry was tested one by one until the ideal value was found. The ntree can roughly judge the value of the error stability in the model by graph. Optimized parameters' value was determined by the root mean square error. The result implies that the optimal model for ANPP was established when ntree was 600 and mtry was 4; for EC, the inversion model was best when ntree was 400 and mtry was $3 . \mathrm{R}^{2}$ of the ANPP and EC models was 0.85 and 0.91 , and RMSE was $15.81 \mathrm{~g} / \mathrm{m}^{2}$ and $0.057 \mathrm{mS} / \mathrm{cm}$, respectively.
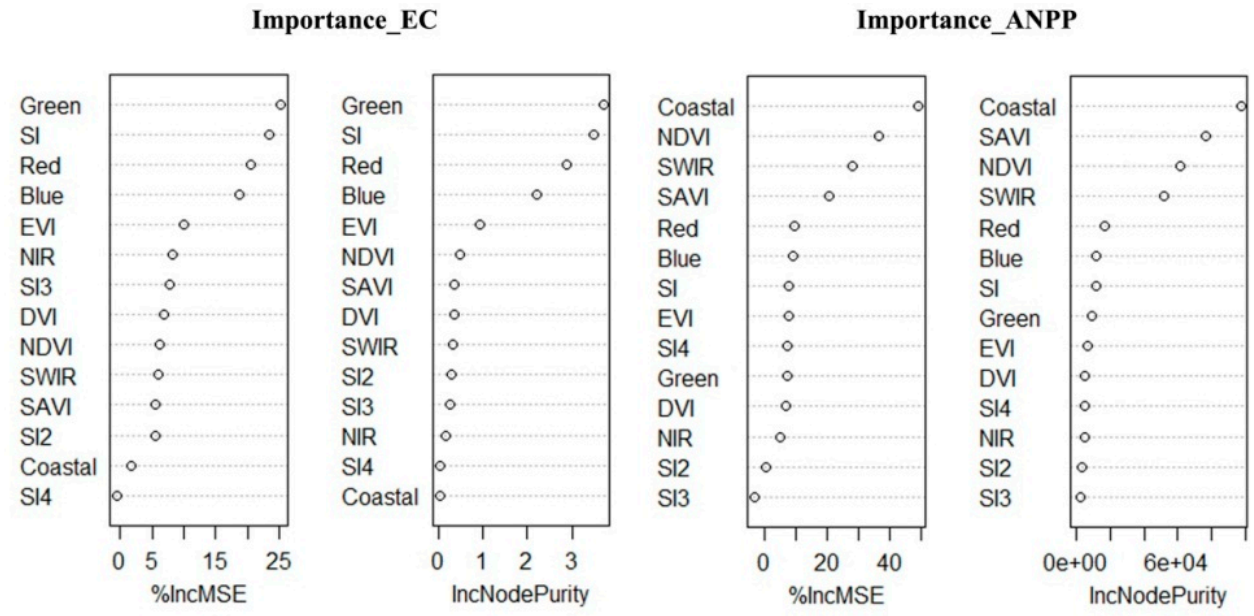

Figure 5. The importance score of variables for estimating aboveground net primary production (ANPP) and electrical conductivity (EC). The higher the importance scores the more important the variable for estimating ANPP and EC. SWIR is Shortwave Infrared; NIR is Near Infrared.

Additionally, we analyzed the spatial distribution of the uncertainty of the inversion models. The introduction of the method has been described in Section 2.2.2. Figure 6 shows the spatial map of uncertainty for grassland degradation parameters. Figure 6a shows that the higher RMSE of the ANPP model was distributed in the north and east of the study area. RMSE in the central region was mainly below $10 \mathrm{gC} / \mathrm{m}^{2}$, and that in northwest of the region was above $20 \mathrm{gC} / \mathrm{m}^{2}$. This means that the model of ANPP was more effective in the central region than the north or the east regions. Figure $6 \mathrm{~b}$ shows that the RMSE of EC below $0.10 \mathrm{mS} / \mathrm{cm}$ nearly covered the entire area except for the central region and a small part of the north region. For the EC model, the predicted values were much higher than the measured values when the value of EC was above $1 \mathrm{mS} / \mathrm{cm}$. 

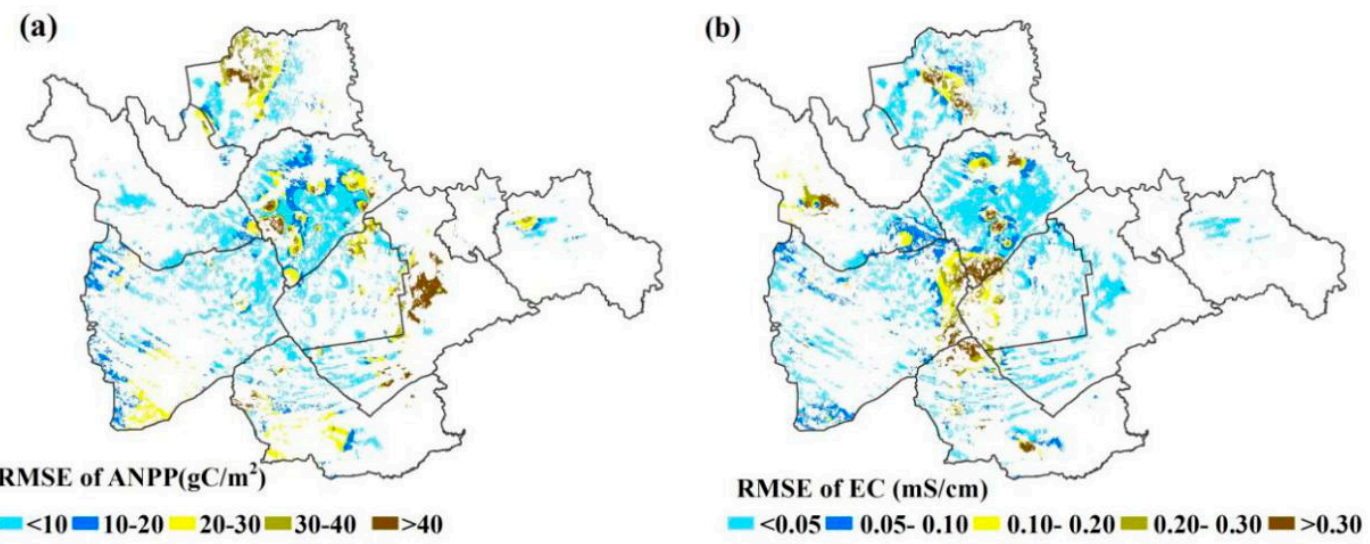

Figure 6. The spatial uncertainties of ANPP and EC models. (a) the spatial uncertainty distribution of ANPP; (b) the spatial uncertainty distribution of EC.

\subsection{Spatial Distribution of ANPP and EC Using RF}

The spatial distribution of grassland in west Jilin Province was obtained by OBIA and using a decision tree. The accuracy of grassland classification was assessed by field survey and random extraction points from higher resolution images. The overall grassland classification accuracy was $92.55 \%$. Larger patches of grassland were mainly distributed in the central and north area, while smaller patches of grassland were scattered in the south of the study area. The grassland area was $606.73 \times 10^{3}$ ha over west Jilin Province in 2017.

The relationships between Landsat OLI imagery and sampling measurements were obtained by RF aiming to predict ANPP and EC. Figure 7 shows the spatial distribution of ANPP and EC over west Jilin Province. The Figure 7a showed that the ANPP value of grassland ranged from $32.912 \mathrm{gC} / \mathrm{m}^{2}$ to $273.794 \mathrm{gC} / \mathrm{m}^{2}$ and the mean value was $106.231 \mathrm{gC} / \mathrm{m}^{2} .44 .45 \%$ of the area had an ANPP value between $75-125 \mathrm{gC} / \mathrm{m}^{2}$, mainly in the central and north regions. $29.79 \%$ of the area had $125-200 \mathrm{gC} / \mathrm{m}^{2}$, concentrated in the central and eastern regions. $17.43 \%$ of the area was below $75 \mathrm{gC} / \mathrm{m}^{2}$ located in the middle regions.
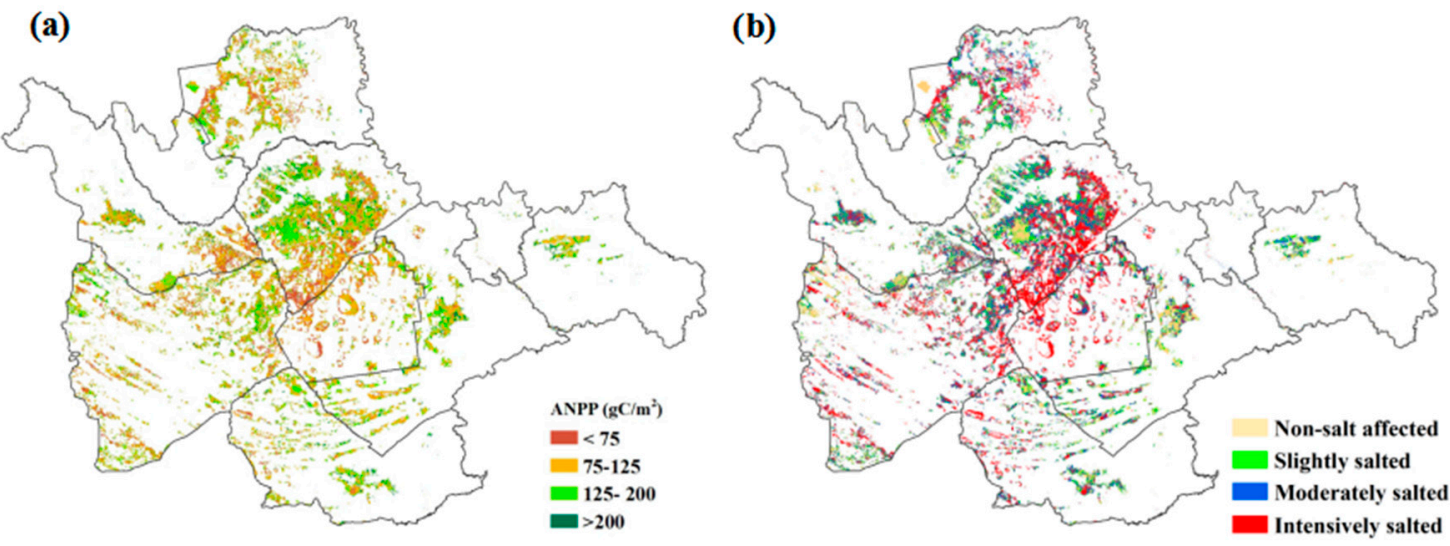

Figure 7. Spatial distribution of EC and ANPP in the West Jilin. (a) the spatial distribution of ANPP; (b) the spatial distribution of soil salinity.

In order to have a clear understanding of the degree of soil salinization in the study area, we ranked four levels for soil salinity using EC. When the value of EC was below $0.2 \mathrm{mS} / \mathrm{cm}$, the region was considered non-salt affected; EC ranging from $0.2 \mathrm{mS} / \mathrm{cm}$ to $0.4 \mathrm{mS} / \mathrm{cm}$ was considered slightly salted; EC ranging from $0.4 \mathrm{mS} / \mathrm{cm}$ to $0.8 \mathrm{mS} / \mathrm{cm}$ was considered moderately salted, and EC above $0.8 \mathrm{mS} / \mathrm{cm}$ was intensively salted. Figure $7 \mathrm{~b}$ showed that the non-salt affected area showed scattered distribution, mainly in the central and eastern parts of the region and only accounts for $16.39 \%$ of the total grassland 
area. Intensively salted regions were concentrated in the low-lying terrain area in the center of the study area, and moderately salted regions were scattered in the middle and south of the area. The salt-affected area was $509.72 \times 10^{3}$ ha, accounting for $83.61 \%$ of the study area; slightly salted was the most common occurrence in salt-affected lands $\left(116.88 \times 10^{3}\right.$ ha), accounting for $19.17 \%$ of the area. The areas of moderately salted and intensively salted were $183.82 \times 10^{3}$ ha and $209.02 \times 10^{3}$ ha, accounting for $30.15 \%$ and $34.28 \%$ of the grassland, respectively.

\subsection{Assessment of Grassland Degradation}

To effectively estimate grassland degradation, we considered both aboveground vegetation and soil salinity (EC) of grassland. Grassland degradation model was established by combining the change rate of EC and ANPP using the PCA method. The covariance matrix was built from the ground sample data. Through matrix decomposition, we obtained two eigenvalues of 0.738 and 0.083 . The first component is defined by the largest eigenvalue 0.738 and the corresponding eigenvector $(-0.261$, $0.685)^{T} . F_{1}$ represents the final data of GDM. The expression of GDM is as follows:

$$
\mathrm{GDM}=F_{1}=-0.224 \times A N P P_{a d j}+0.588 \times E C_{a d j}
$$

$A N P P_{a d j}$ and $E C_{a d j}$ are adjusted ANPP and EC, respectively.

The map of grassland degradation was obtained by the above model. The first principal component contains more information than ANPP or EC, respectively. We classified the first component to four levels (non-degraded, slightly degraded, moderately degraded and intensively degraded) referenced on China's grassland degradation classification indicator studies [81] and China's national standard of "parameters for degradation, sandification, and salification of rangelands" (GB19377-2003) [23,28]. The evaluation of non-degraded grassland in the national standard is based on the characteristics of surface vegetation and soil conditions of the same grassland types in the same hydrothermal conditions near the monitoring area [82]. The results showed that the intensively degraded grassland almost coincided with the intensively salted-affected area, and the values of ANPP in the intensively degraded region were less than $75 \mathrm{gC} / \mathrm{m}^{2}$. The slightly degraded areas of grassland were mainly distributed in the moderately salt-affected and slightly salt-affected areas where the values of ANPP above $125 \mathrm{gC} / \mathrm{m}^{2}$. For moderately degraded region of grassland, the values of ANPP ranged from 55 to $125 \mathrm{gC} / \mathrm{m}^{2}$. This part of the grassland was located on the moderately salt-affected and intensively salt-affected areas. The results of statistical analysis show that $61.31 \%$ of grassland was degraded; the area was $373.78 \times 10^{3}$ ha. Figure 8 shows that the non-degraded area of grassland was located in the center and east of the study area, the intensively degraded area was located in the middle and north of the area, the moderately degraded area was scattered throughout the whole region, and slightly degraded area was mainly located on the west of the area. Intensively degraded land was most common in the grassland degraded area, accounting for $34.52 \%$, followed by moderately degraded land. The moderately degraded area was $88.29 \times 10^{3}$ ha. There was only $12.30 \%$ grassland showing as slightly degraded; the area was $75.01 \times 10^{3}$ ha. 


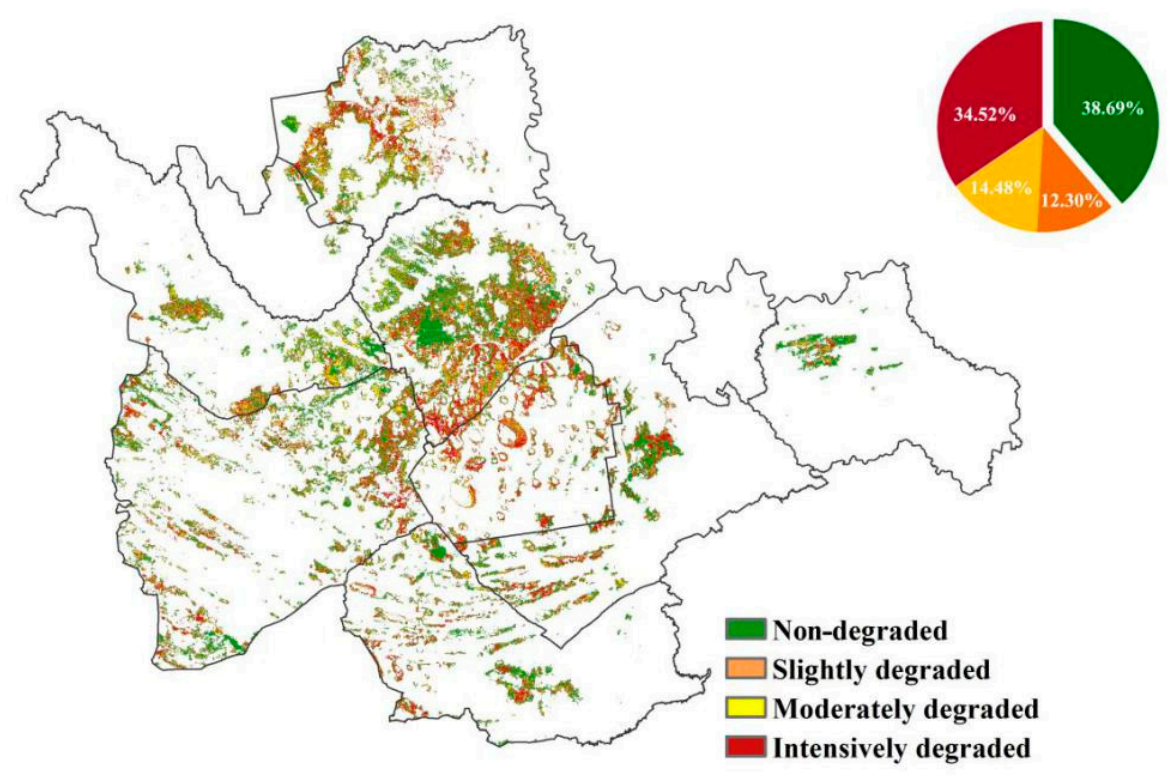

Figure 8. Spatial distribution of different grassland degradation degrees over West Jilin in 2017.

\section{Discussion}

\subsection{Random Forest versus Partial Least Squares Regression}

To better demonstrate the advantages of the RF method in predicting grassland degradation parameters, we compared the prediction results of the RF and PLSR methods. The PLSR is an extension of multiple regression analysis, in which the effects of linear combinations of several predictors on a response variable (or multiple response variables) are analyzed. Some researchers used PLSR to estimate the biomass [83] and EC in the past $[84,85]$. PLSR uses its inferable ability to simulate the possible linear relationship between spectral reflectivity and measured ground data. At the same time, PLSR can also include multiple response variables to effectively deal with strong noise and collinearity of predictive variables [86]. PLSR takes advantage of additional variables or non-linear preprocessing of variables to deal with the non-linearity situation. However, the strategy of using additional factors would cause over-fitting and reduce its real prediction ability [87]. RF could use averaging to improve the predictive accuracy and control over-fitting.

Table 2 shows the result of estimating ANPP and EC using PLSR. For ANPP, the inversion models implied that NDVI and SWIR were the best variables. For the EC model, the most influential variable was the Green band. In our previous study, we found that the Green reflection rose significantly when the EC value was above $1 \mathrm{mS} / \mathrm{cm}$, which explained why the inversion results of the power exponent model had high accuracy [39].

Validation data $(n=50)$ was used to validate the predictive performance of the models. Figure 9 shows the accuracy of the RF and PLSR models. The validation results show that the $\mathrm{R}^{2}$ of the RF models were significantly higher than the PLSR model. Figure 9 a,c showed the relationship between actual value and predicted value by RF; Figure $9 b$, d showed the relationship by PLSR. For ANPP, the $\mathrm{R}^{2}$ increased from 0.57 to 0.87 and from 0.81 to 0.95 for EC. These inversion models which were established by RF had the highest $R^{2}$ and lowest RMSE. The RF models explained over $85 \%$ of ANPP/EC variation, with RMSE of $13.13 \mathrm{gC} / \mathrm{m}^{2}$ and $0.046 \mathrm{mS} / \mathrm{cm}$, respectively. The results indicated that RF is a more suitable technique than PLSR for the estimation and mapping of ANPP and EC. 
Table 2. The model comparisons of grassland degradation parameters.

\begin{tabular}{|c|c|c|c|}
\hline Type of Model & ANPP & $\mathbf{R}^{2}$ & $\operatorname{RSME}\left(\mathrm{gC} / \mathrm{m}^{2}\right)$ \\
\hline Linear & $\mathrm{ANPP}=234.561 \mathrm{NDVI}+34.067$ & $0.540 * *$ & 20.696 \\
\hline Polynomial & $\mathrm{ANPP}=133.798 \mathrm{NDVI}^{2}+153.18 \mathrm{NDVI}+43.186$ & $0.545^{* *}$ & 20.592 \\
\hline Exponential & $\mathrm{ANPP}=43.896 \mathrm{e}^{2.494 \mathrm{NDVI}}$ & $0.529 * *$ & 21.065 \\
\hline LTU & $\mathrm{ANPP}=256.824+351.608 \mathrm{NDVI}-287.695 \mathrm{SWIR}$ & $0.571^{* *}$ & 20.048 \\
\hline Type of Model & EC & $\mathbf{R}^{2}$ & $\operatorname{RSME}(\mathrm{mS} / \mathrm{cm})$ \\
\hline Linear & $\mathrm{EC}=4.2862 \mathrm{Green}-0.5525$ & $0.682 * *$ & 0.471 \\
\hline Polynomial & $\mathrm{EC}=7.1997 \mathrm{Green}^{2}-0.7424 \mathrm{Green}+0.0748$ & $0.735 * *$ & 0.437 \\
\hline Power exponent & $\mathrm{EC}=3.982$ Green $^{1.867}$ & $0.738^{* *}$ & 0.429 \\
\hline LTU & $\mathrm{EC}=6.296$ Green $-1.982 \mathrm{SWIR}-0.186$ & $0.703 *$ & 0.452 \\
\hline
\end{tabular}

* represents significance at the 0.05 level; ${ }^{* *}$ represents significance at the 0.01 level; bold number means the maximum value in a column; LTU means linear equation in two unknowns. The unit for ANPP was $\mathrm{gC} / \mathrm{m}^{2}$, and unit for EC was $\mathrm{mS} / \mathrm{cm}$.
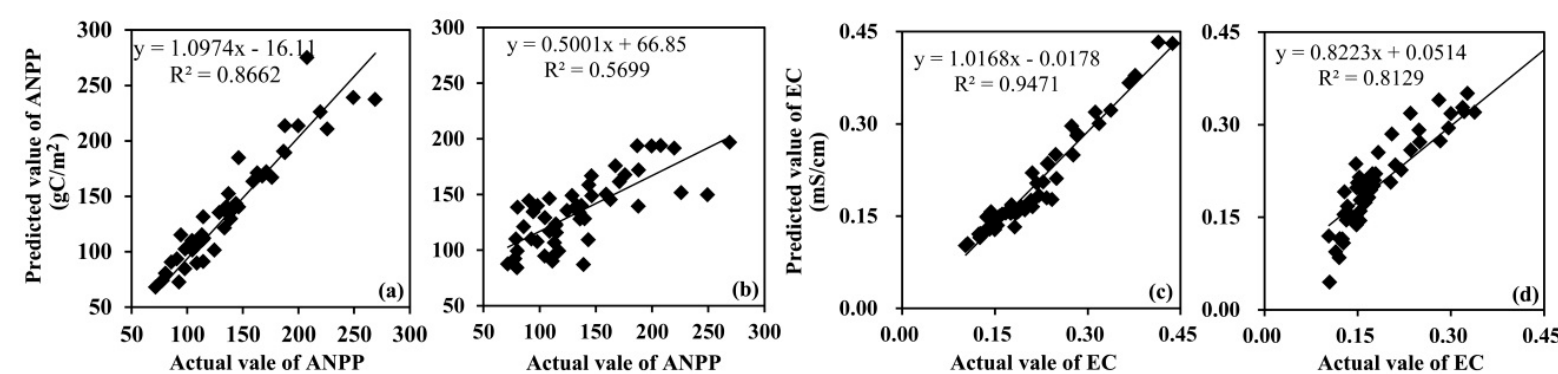

Figure 9. Relationships between predicted ANPP/EC and measured ANPP/EC of grassland. (a) ANPP model using RF; (b) ANPP model using PLSR; (c) EC model using RF; (d) EC model using PLSR.

RF has integrated learning, both variance and deviation are relatively low, and the generalization performance is superior compared with classical regression trees. RF can provide an effective method to balance the error of datasets when there is an imbalance in classification. Because RF is a tree model, we can use it directly without normalization. Although RF resembles the "black box" method more than PLSR, it still interprets the meaning of decision trees by variable importance [88].

\subsection{The Importance of Soil Salinity}

The west Jilin Province is an ecologically sensitive and fragile zone with a wide area of soil salinization and is one of only three alkali lands in the world. Soil salinization seriously restricts the development of natural steppes and animal husbandry [42]. Soil salinity is a major driving factor of grassland degradation. Numerous grasslands are distributed on the salted soils in west Jilin province, and the issue of grassland soil salinization is attracting increasing attention. With the exacerbation of soil salinization, the exposed proportion of alkali spots significantly increased $[39,54]$. Soil salinization is one of the major factors restricting the sustainable development of ecology in the west of Jilin province, reducing the production of vegetation, increasing the proportion of non-palatable grassland, and affecting the diversity of vegetation species [22,39]. Figure 10 shows the different statuses of grasslands at different levels of soil salinity; Figure 10a showed the grassland coverage, the coverage rate from high to low is a1 $>$ a $3>$ a $4>$ a2, Figure 10b showed the levels of salt-affected soil, the order of soil salinization is $b 3>b 2>b 4>b 1$ from high to low. The soil salt level in Figure 10b3 was higher than other samples; however, the plant coverage was not the lowest. If the grassland degradation model only focused on the grassland cover or yield of grass, this situation would be mistaken for non-degraded areas. In fact, with the increase of soil salinization, the rate of dominant grass species has decreased. GMD overcame the over-reliance on grassland coverage and grass production ability to analyze grassland degradation and produced an effective model which was closer to the actual situation. 
Due to soil salinity, $83.61 \%$ of grasslands were salt-affected regions. Moreover, the moderately and intensively salted regions were the most common types in salt-affected grassland areas. Therefore, the salinization of grassland is a factor that cannot be ignored in the evaluation of grassland degradation.

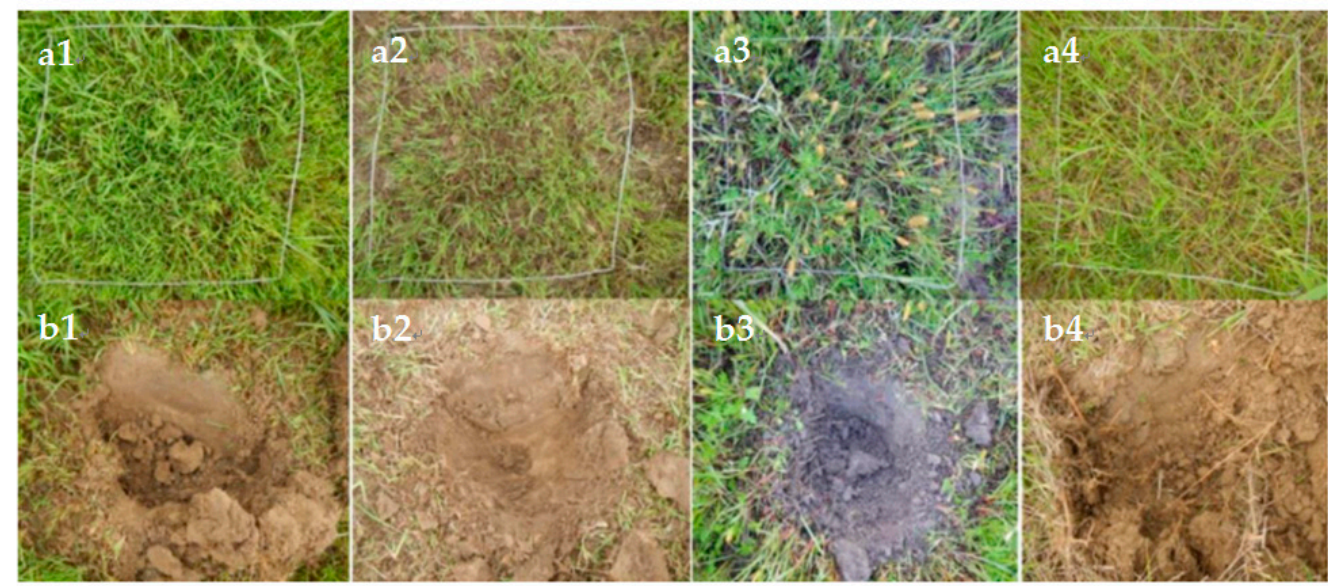

Figure 10. The field sampling pictures of the grassland in 2017. (a1)-(a4) the condition of grass coverage in sampling points; (b1)-(b4) the soil salinity of the corresponding sampling points.

In past studies, the total area of grassland decreased and grassland was the most severely salt-affected vegetation type in past decades $[7,16,39]$. Moreover, soil salinity is the key factor of grassland degradation in west Jilin Province [89]. In this paper, we realized that the extremely salted areas had high correlation with strongly degraded grassland. It was found that the health and prosperity of grasslands are highly correlated with soil status; however, this notion is not clearly pointed out in most grassland degradation studies, and soil salinity was seldom integrated into the model calculation of grassland degradation. In previous studies, more attention has been paid to aboveground biomass, plant coverage, and species of vegetation than soil properties in estimating grassland degradation. This groundbreaking study achieves a comprehensive evaluation of grassland degradation from a new point of view.

\subsection{Uncertainties of Grassland Degradation}

Remote sensing offers multiple sensing technologies to monitor grassland degradation. Monitoring grassland degradation via establishing models using measurements and satellite imagery has become much more reliable means compared with traditional methods. There are two major problems facing the assessment of degradation: (i) the uncertainty of baseline assessments and indicator systems and (ii) the misuse of remotely sensed data sources. Liu et al. assessed the grade of grassland degradation using the grass coverage ratio and the proportion of unpalatable grasses, which were sampled by $1 \mathrm{~m}^{2}$ plots; then the risk of degradation model of grassland was obtained by weighted summation with a weight of 0.5 assigned to each parameter [24]. Wei et al. realized the grassland degradation by change rates of grassland cover and NPP, and then quantitatively assessed the contribution of driving forces [8]. Some studies assessed the grassland degradation by interpreting remote imagery with different levels [90]. In these studies, there was some uncertainty in grassland degradation, caused by the selection of degradation indicators and weights allocation of assessment indicators. Moreover, the image resolutions, influence of bands, interpreter's cognition for study area, and professional skills have an impact on the results of grassland degradation. Previous studies show that the spatial distribution of the grassland was primarily affected by the salt in the surface soil over semi-arid or arid regions [37]. In our paper, we selected ANPP and soil salinity as the research parameters of grassland degradation system according to the soil characteristics of west Jilin Province. Moreover, in weight distribution of parameters, we use the PCA method instead of artificial decision to reduce the 
uncertainty caused by human interference. Although we have ameliorated the grassland degradation assessment method, there are still some uncertainties. Figure 6 shows the spatial uncertainties of ANPP and EC models and how to reduce the higher RMSE in the south and eastern regions. Further improving the accuracy of grassland degradation is the main focus of our future research.

\section{Conclusions}

In this research, we assessed grassland degradation by not only its coverage but also its quality and productivity. We established a new grassland degradation model, which was specially designed for semiarid regions, based on aboveground net primary production and soil salinity using 166 field samplings. The grassland degradation parameters were assessed by RF verifying the relationship with spectral indices and individual bands from the satellite images. The result shows that the RMSE of ANPP was $15.81 \mathrm{gC} / \mathrm{m}^{2}\left(\mathrm{R}^{2}=0.85\right)$ and that of EC was $0.057 \mathrm{mS} / \mathrm{cm}\left(\mathrm{R}^{2}=0.91\right)$. GMD was obtained by estimating ANPP and EC using PAC. GMD revealed $61.31 \%$ of grassland was degraded in the study area. Intensively degraded land was most common in the grassland degraded area, accounting for $34.52 \%$ of the area, followed by moderately degraded. The moderately degraded area was $88.29 \times 10^{3}$ ha. Only $12.30 \%$ of grassland showed slight degradation, and the area was $75.01 \times 10^{3}$ ha. Our results demonstrate that our method is a viable solution to grassland degradation monitoring through remote sensing and in-situ data collection of ANPP and EC. In addition, government-aided restoration and protection measures should be implemented in a routine manner, with higher intensity, to minimize future grassland degradation in the west Jilin Province of China.

Author Contributions: Hao Yu and Zongming Wang conceived and designed the research; Hao Yu processed the data, performed the experiments and wrote the manuscript draft; Chunying Ren conducted the fieldwork, helped to design the research and reviewed the manuscript; Bai Zhang contributed reagents/materials/analysis tools; Hao Yu prepared all figures and tables. Zongming Wang, Chunying Ren and Lei Wang helped to conceive the research and reviewed the manuscript.

Funding: This research was funded the Strategic Priority Research Program of the Chinese Academy of Sciences (XDA19040500), the Key Project for Field Station Alliance, Chinese Academy of Sciences (KFJ-SW-YW026), the Program Founding from IGA (Y6H2091001), the funding from Youth Innovation Promotion Association Chinese Academy of Sciences $(2017277,2012178)$, the funding from Jilin Scientific and Technological Development Program (20170301001NY), and funding from the China Scholarship Council (CSC NO. 201804910494).

Conflicts of Interest: The authors declare no conflict of interest.

\section{References}

1. Piao, S.; Fang, J.; He, J.; Xiao, Y. Spatial distribution of grassland biomass in China. Acta Phyto Sin. 2004, 28, 491-498. (In Chinese)

2. Scurlock, J.M.; Johnson, K.; Olson, R.J. Estimating net primary productivity from grassland biomass dynamics measurements. Glob. Chang. Biol. 2002, 8, 736-753. [CrossRef]

3. Carlier, L.; Rotar, I.; Vlahova, M.; Vidican, R. Importance and functions of grasslands. Not. Bot. Horti Agrobot. Cluj Napoca 2009, 37, 25-30.

4. Sperling, K. What Are the Functions of the Grassland Ecosystem. Available online: https://sciencing.com/ functions-grassland-ecosystem-5681746.html (accessed on 2 December 2018).

5. Wang, Z.; Deng, X.Z.; Song, W.; Li, Z.H.; Chen, J.C. What is the main cause of grassland degradation? A case study of grassland ecosystem service in the middle-south Inner Mongolia. Catena 2017, 150, 100-107. [CrossRef]

6. Hao, L.; Sun, G.; Liu, Y.; Gao, Z.; He, J.; Shi, T.; Wu, B. Effects of precipitation on grassland ecosystem restoration under grazing exclusion in Inner Mongolia, China. Landsc. Ecol. 2014, 29, 1657-1673. [CrossRef]

7. Fei, L.; Zhang, S.; Yang, J.; Chang, L.; Yang, H.; Bu, K. Effects of land use change on ecosystem services value in West Jilin since the reform and opening of China. Ecosyst. Serv. 2018, 31, 12-20. [CrossRef]

8. Feng, Y.; Lu, Q.; Tokola, T.; Liu, H.; Wang, X. Assessment of Grassland Degradation in Guinan County, Qinghai Province, China, in the Past 30 Years. Land Degrad. Dev. 2009, 20, 55-68. [CrossRef] 
9. Wang, Z.; Song, K.; Zhang, B.; Liu, D.; Ren, C.; Luo, L.; Yang, T.; Huang, N.; Hu, L.; Yang, H.; et al. Shrinkage and fragmentation of grasslands in the West Songnen Plain, China. Agric. Ecosyst. Environ. 2009, 129, 315-324. [CrossRef]

10. Andrade, B.O.; Koch, C.; Boldrini, I.I.; Velez-Martin, E.; Hasenack, H.; Hermann, J.M.; Kollmann, J.; Pillar, V.D.; Overbeck, G.E. Grassland degradation and restoration: A conceptual framework of stages and thresholds illustrated by southern Brazilian grasslands. Nat. Conserv. 2015, 13, 95-104. [CrossRef]

11. Liu, J.; Diamond, J. China's environment in a globalizing world. Nature 2005, 435, 1179-1186. [CrossRef] [PubMed]

12. Liu, J.; Kuang, W.; Zhang, Z.; Xu, X.; Qin, Y.; Ning, J.; Zhou, W.; Zhang, S.; Li, R.; Yan, C. Spatiotemporal characteristics, patterns, and causes of land-use changes in China since the late 1980s. J. Geogr. Sci. 2014, 24, 195-210. [CrossRef]

13. Dai, G.; Ulgiati, S.; Zhang, Y.; Yu, B.; Kang, M.; Jin, Y.; Dong, X.; Zhang, X. The false promises of coal exploitation: How mining affects herdsmen well-being in the grassland ecosystems of Inner Mongolia. Energy Policy 2014, 67, 146-153. [CrossRef]

14. Fang, L.; Zhang, B.; Su, W.; He, Y.; Wang, Z.; Song, K.; Liu, D.; Liu, Z. Sandy desertification change and its driving forces in western Jilin Province, North China. Environ. Monit. Assess. 2008, 136, 379-390. [CrossRef] [PubMed]

15. Wu, J.; Vincent, B.; Yang, J.; Bouarfa, S.; Vidal, A. Remote Sensing Monitoring of Changes in Soil Salinity: A Case Study in Inner Mongolia, China. Sensors 2008, 8, 7035-7049. [CrossRef] [PubMed]

16. Bai, L.; Wang, C.Z.; Zang, S.Y.; Zhang, Y.H.; Hao, Q.N.; Wu, Y.X. Remote Sensing of Soil Alkalinity and Salinity in the Wuyu'er-Shuangyang River Basin, Northeast China. Remote Sens. 2016, 8, 163. [CrossRef]

17. Zou, Y.; Zhang, Z.; Zhou, Q.; Zhao, X.; Liu, B. Spatial pattern and its analysis of China's grassland change in recent ten years using remote sensing and GIS. J. Remote Sens. 2003, 7, 428-432. (In Chinese)

18. Drummond, M.A. Regional dynamics of grassland change in the western Great Plains. Gt. Plains Res. 2007, 17, 133-144.

19. Ali, I.; Cawkwell, F.; Dwyer, E.; Barrett, B.; Green, S. Satellite remote sensing of grasslands: From observation to management. J. Plant Ecol. 2016, 9, 649-671. [CrossRef]

20. Nendel, C.; Hu, Y.; Lakes, T. Land-use change and land degradation on the Mongolian Plateau from 1975 to 2015-A case study from Xilingol, China. Land Degrad. Dev. 2018, 29, 1595-1606.

21. Hou, X.; Zhuang, D.; Yu, X. Grassland Change and Its Spatial Patterns in Xinjiang in 1990s. Acta Geogr. Sin. 2004, 59, 409-417. (In Chinese)

22. Li, F.; Jiang, L.; Wang, X.; Zhang, X.; Zheng, J.; Zhao, Q. Estimating grassland aboveground biomass using multitemporal MODIS data in the West Songnen Plain, China. J. Appl. Remote Sens. 2013, 7, 073546. [CrossRef]

23. Gao, Q.; Wan, Y.; Xu, H.; Li, Y.; Wang, J.; Borjigidai, A. Alpine grassland degradation index and its response to recent climate variability in Northern Tibet, China. Quat. Int. 2010, 226, 143-150. [CrossRef]

24. Liu, Y.; Zha, Y.; Gao, J.; Ni, S. Assessment of grassland degradation near Lake Qinghai, West China, using Landsat TM and in situ reflectance spectra data. Int. J. Remote Sens. 2004, 25, 4177-4189. [CrossRef]

25. Zhang, Y.; Wang, K.; Yang, Y.; Li, J.; Zhang, Y.; Zhang, C. Research on the quantitative evaluation of grassland degradation and spatial and temporal distribtution on the Mongolia Plateau. Partacult. Sci. 2018, 35, $233-243$.

26. Tarantino, C.; Adamo, M.; Lucas, R.; Blonda, P. Detection of changes in semi-natural grasslands by cross correlation analysis with WorldView-2 images and new Landsat 8 data. Remote Sens. Environ. 2016, 175, 65-72. [CrossRef] [PubMed]

27. Wang, H.J.; Fan, W.J.; Cui, Y.K.; Zhou, L.; Yan, B.Y.; Wu, D.H.; Xu, X.R. Hyperspectral Remote Sensing Monitoring of Grassland Degradation. Spectrosc. Spectr. Anal. 2010, 30, 2734-2738.

28. Liu, J.Y.; Xu, X.L.; Shao, Q.Q. Grassland degradation in the "Three-River Headwaters" region, Qinghai Province. J. Geogr. Sci. 2008, 18, 259-273. [CrossRef]

29. Lu, B.; He, Y. Species classification using Unmanned Aerial Vehicle (UAV)-acquired high spatial resolution imagery in a heterogeneous grassland. ISPRS J. Photogramm. Remote Sens. 2017, 128, 73-85. [CrossRef]

30. Zhang, X.F.; Niu, J.M.; Buyantuev, A.; Zhang, Q.; Dong, J.J.; Kang, S.; Zhang, J. Understanding Grassland Degradation and Restoration from the Perspective of Ecosystem Services: A Case Study of the Xilin River Basin in Inner Mongolia, China. Sustainability 2016, 8, 594. [CrossRef] 
31. Jing, L.; Jian, W. Estimating Plant Biomass in Jun Ma Chang of Shandan County Using Landsat TM Data. Remote Sens. Technol. Appl. 2011, 19, 343-347.

32. Imhoff, M.L.; Bounoua, L.; Ricketts, T.; Loucks, C.; Harriss, R.; Lawrence, W.T. Global patterns in human consumption of net primary production. Nature 2004, 429, 870-873. [CrossRef] [PubMed]

33. Luo, L.; Wang, Z.; Mao, D.; Lou, Y.; Ren, C.; Song, K. Response of grassland net primary productivity in western Songnen Plain of northeast China to climate change and human activity. Chin. J. Ecol. 2012, 31, 1533-1540.

34. Knapp, A.K.; Smith, M.D. Variation among biomes in temporal dynamics of aboveground primary production. Science 2001, 291, 481-484. [CrossRef] [PubMed]

35. Piao, S.; Fang, J. Terrestrial net primary production and its spatio-temporal patterns in Qinghai-Xizang Plateau, China during 1982-1999. J. Nat. Conserv. 2002, 17, 373-380.

36. Li, J.; Yang, X.; Jin, Y.; Yang, Z.; Huang, W.; Zhao, L.; Gao, T.; Yu, H.; Ma, H.; Qin, Z.; et al. Monitoring and analysis of grassland desertification dynamics using Landsat images in Ningxia, China. Remote Sens. Environ. 2013, 138, 19-26. [CrossRef]

37. Lin, J.; Wang, J.; Li, X.; Zhang, Y.; Xu, Q.; Mu, C. Effects of saline and alkaline stresses in varying temperature regimes on seed germination of Leymus chinensis from the Songnen Grassland of China. Grass Forage Sci. 2011, 66, 578-584. [CrossRef]

38. Wu, L.; Li, Q. Research of mechanism of saline desertification in Western Songnen Plain. J. Soil Water Conserv. 2003, 17, 79-81. (In Chinese)

39. Yu, H.; Liu, M.; Du, B.; Wang, Z.; Hu, L.; Zhang, B. Mapping Soil Salinity/Sodicity by using Landsat OLI Imagery and PLSR Algorithm over Semiarid West Jilin Province, China. Sensors 2018, 18, 1048. [CrossRef] [PubMed]

40. Han, D.M.; Wang, G.Q.; Xue, B.L.; Liu, T.X.; A, Y.L.; Xu, X.Y. Evaluation of semiarid grassland degradation in North China from multiple perspectives. Ecol. Eng. 2018, 112, 41-50. [CrossRef]

41. Jiang, S.; Zhou, D.; Jin, Y. Characteristic of moisture and salt dynamic in saline-alkalized grassland of Songnen Plain during thawing period. J. Northeast Norm. Univ. 2006, 38, 124. (In Chinese)

42. Eldridge, D.J.; Wong, V.N.L. Clumped and isolated trees influence soil nutrient levels in an Australian temperate box woodland. Plant Soil 2005, 270, 331-342. [CrossRef]

43. Farifteh, J.; Van der Meer, F.; Atzberger, C.; Carranza, E.J.M. Quantitative analysis of salt-affected soil reflectance spectra: A comparison of two adaptive methods (PLSR and ANN). Remote Sens. Environ. 2007, 110, 59-78. [CrossRef]

44. Mutanga, O.; Adam, E.; Cho, M.A. High density biomass estimation for wetland vegetation using WorldView-2 imagery and random forest regression algorithm. Int. J. Appl. Earth Obs. Geoinf. 2012, 18, 399-406. [CrossRef]

45. Ramoelo, A.; Cho, M.A.; Mathieu, R.; Madonsela, S.; Van De Kerchove, R.; Kaszta, Z.; Wolff, E. Monitoring grass nutrients and biomass as indicators of rangeland quality and quantity using random forest modelling and WorldView-2 data. Int. J. Appl. Earth Obs. Geoinf. 2015, 43, 43-54. [CrossRef]

46. Barandiaran, I. The random subspace method for constructing decision forests. IEEE Trans. Pattern Anal. Mach. Intell. 1998, 20, 1-22.

47. Chen, L.; Wang, Y.; Ren, C.; Zhang, B.; Wang, Z. Assessment of multi-wavelength SAR and multispectral instrument data for forest aboveground biomass mapping using random forest kriging. For. Ecol. Manag. 2019, 447, 12-25. [CrossRef]

48. Ma, H.; Lv, B.; Li, X.; Liang, Z. Germination Response to Differing Salinity Levels for 18 Grass Species from the Saline-alkaline Grasslands of the Songnen Plain, China. Pak. J. Bot. 2014, 46, 1147-1152.

49. Liu, B.; Guo, J. The Grassland Ecosystem Services Value in the West Jilin Province. Grassl. China 2005, 27, 2-21. (In Chinese)

50. Wang, Z.; Zhang, Y.; Zhang, B.; Song, K.; Guo, Z.; Liu, D.; Li, F. Landscape dynamics and driving factors in Da'an County of Jilin Province in Northeast China during 1956-2000. Chin. Geogr. Sci. 2008, 18, 137-145. [CrossRef]

51. Moiwo, J.P.; Lu, W.; Zhao, Y.; Yang, Y.; Yang, Y. Impact of land use on distributed hydrological processes in the semi-arid wetland ecosystem of Western Jilin. Hydrol. Process. 2010, 24, 492-503. [CrossRef]

52. Mao, D.; He, X.; Wang, Z.; Tian, Y.; Xiang, H.; Yu, H.; Man, W.; Jia, M.; Ren, C.; Zheng, H. Diverse policies leading to contrasting impacts on land cover and ecosystem services in Northeast China. J Clean. Prod. 2019, 240, 117961. [CrossRef] 
53. Cao, C.Y.; Zhang, Y.; Qian, W.; Liang, C.P.; Wang, C.M.; Tao, S. Land-use changes influence soil bacterial communities in a meadow grassland in Northeast China. Solid Earth 2017, 8, 1119-1129. [CrossRef]

54. Li, F.; Zhang, S.; Bu, K.; Yang, J.; Wang, Q.; Chang, L. The relationships between land use change and demographic dynamics in western Jilin province. J. Geogr. Sci. 2015, 25, 617-636. [CrossRef]

55. Wu, W.; Mhaimeed, A.S.; Al-Shafie, W.M.; Ziadat, F.; Dhehibi, B.; Nangia, V.; De Pauw, E. Mapping soil salinity changes using remote sensing in Central Iraq. Geoderma Reg. 2014, 2-3, 21-31. [CrossRef]

56. Shrestha, R.P. Relating soil electrical conductivity to remote sensing and other soil properties for assessing soil salinity in northeast Thailand. Land Degrad. Dev. 2006, 17, 677-689. [CrossRef]

57. Jia, M.; Wang, Z.; Wang, C.; Mao, D.; Zhang, Y. A New Vegetation Index to Detect Periodically Submerged Mangrove Forest Using Single-Tide Sentinel-2 Imagery. Remote Sens. 2019, 11, 2043. [CrossRef]

58. Jiang, Z.; Huete, A.; Didan, K.; Miura, T. Development of a two-band enhanced vegetation index without a blue band. Remote Sen. Environ. 2008, 112, 3833-3845. [CrossRef]

59. Alhammadi, M.S.; Glenn, E.P. Detecting date palm trees health and vegetation greenness change on the eastern coast of the United Arab Emirates using SAVI. Int. J. Remote Sens. 2008, 29, 1745-1765. [CrossRef]

60. Bouaziz, M.; Matschullat, J.; Gloaguen, R. Improved remote sensing detection of soil salinity from a semi-arid climate in Northeast Brazil. CR Geosci. 2011, 343, 795-803. [CrossRef]

61. Douaoui, A.E.K.; Nicolas, H.; Walter, C. Detecting salinity hazards within a semiarid context by means of combining soil and remote-sensing data. Geoderma 2006, 134, 217-230. [CrossRef]

62. Byrne, K.M.; Lauenroth, W.K.; Adler, P.B.; Byrne, C.M. Estimating aboveground net primary production in grasslands: A comparison of nondestructive methods. Rangel Ecol. Manag. 2011, 64, 498-505. [CrossRef]

63. Chen, S.; Wang, S.; Zhou, Y. Estimation of Chinese grassland productivity using remote sensing. Trans. CSAE 2008, 24, 208-212. (In Chinese)

64. Zhang, T.-T.; Qi, J.-G.; Gao, Y.; Ouyang, Z.-T.; Zeng, S.-L.; Zhao, B. Detecting soil salinity with MODIS time series VI data. Ecol. Indic. 2015, 52, 480-489. [CrossRef]

65. Jawak, S.D.; Devliyal, P.; Luis, A.J. A comprehensive review on pixel oriented and object oriented methods for information extraction from remotely sensed satellite images with a special emphasis on cryospheric applications. Adv. Remote Sens. 2015, 4, 177. [CrossRef]

66. Hussain, M.; Chen, D.; Cheng, A.; Wei, H.; Stanley, D. Change detection from remotely sensed images: From pixel-based to object-based approaches. ISPRS J. Photogramm. Remote Sens. 2013, 80, 91-106. [CrossRef]

67. Hellesen, T.; Matikainen, L. An object-based approach for mapping shrub and tree cover on grassland habitats by use of LiDAR and CIR orthoimages. Remote Sens. 2013, 5, 558-583. [CrossRef]

68. Zhang, X.L.; Xiao, P.F.; Song, X.Q.; She, J.F. Boundary-constrained multi-scale segmentation method for remote sensing images. ISPRS J. Photogram. 2013, 78, 15-25. [CrossRef]

69. Otukei, J.R.; Blaschke, T. Land cover change assessment using decision trees, support vector machines and maximum likelihood classification algorithms. Int. J. Appl. Earth Obs. Geoinf. 2010, 12, S27-S31. [CrossRef]

70. Elnaggar, A.; Noller, J. Application of remote-sensing data and decision-tree analysis to mapping salt-affected soils over large areas. Remote Sens. 2010, 2, 151-165. [CrossRef]

71. de Colstoun, E.C.B.; Walthall, C.L. Improving global scale land cover classifications with multi-directional POLDER data and a decision tree classifier. Remote Sens. Environ. 2006, 100, 474-485. [CrossRef]

72. Breiman, L. Random forests. Mach. Learn. 2001, 45, 5-32. [CrossRef]

73. Rodriguez-Galiano, V.F.; Ghimire, B.; Rogan, J.; Chica-Olmo, M.; Rigol-Sanchez, J.P. An assessment of the effectiveness of a random forest classifier for land-cover classification. ISPRS J. Photogram. 2012, 67, 93-104. [CrossRef]

74. Pal, M. Random forest classifier for remote sensing classification. Int. J Remote Sens. 2005, 26, $217-222$. [CrossRef]

75. Ließ, M.; Glaser, B.; Huwe, B. Uncertainty in the spatial prediction of soil texture: Comparison of regression tree and Random Forest models. Geoderma 2012, 170, 70-79. [CrossRef]

76. Guo, L.; Chehata, N.; Mallet, C.; Boukir, S. Relevance of airborne lidar and multispectral image data for urban scene classification using Random Forests. ISPRS J. Photogram. 2011, 66, 56-66. [CrossRef]

77. Huang, H.; Liu, C.; Wang, X.; Zhou, X.; Gong, P. Integration of multi-resource remotely sensed data and allometric models for forest aboveground biomass estimation in China. Remote Sens. Environ. 2019, 221, 225-234. [CrossRef] 
78. Martens, H.; Martens, M. Modified Jack-knife estimation of parameter uncertainty in bilinear modelling by partial least squares regression (PLSR). Food Qual. Prefer. 2000, 11, 5-16. [CrossRef]

79. Ringnér, M. What is principal component analysis? Nat. Biotechnol. 2008, 26, 303-304. [CrossRef] [PubMed]

80. Vincenzi, S.; Zucchetta, M.; Franzoi, P.; Pellizzato, M.; Pranovi, F.; De Leo, G.A.; Torricelli, P. Application of a Random Forest algorithm to predict spatial distribution of the potential yield of Ruditapes philippinarum in the Venice lagoon, Italy. Ecol. Model. 2011, 222, 1471-1478. [CrossRef]

81. Li, S.; Verburg, P.H.; Lv, S.; Wu, J.; Li, X. Spatial analysis of the driving factors of grassland degradation under conditions of climate change and intensive use in Inner Mongolia, China. Reg. Environ. Chang. 2012, 12, 461-474. [CrossRef]

82. Gao, Q.; Li, Y.; Lin, E.; Jiangcun, W.; Wan, Y.; Xiong, W.; Wang, B.; Li, W. Temporal and spatial distribution of grassland degradation in Northern Tibet. Acta Geogr. Sin. 2005, 60, 965-973. (In Chinese)

83. Jin, X.; Yang, G.; Xu, X.; Yang, H.; Feng, H.; Li, Z.; Shen, J.; Lan, Y.; Zhao, C. Combined multi-temporal optical and radar parameters for estimating LAI and biomass in winter wheat using HJ and RADARSAR-2 data. Remote Sens. 2015, 7, 13251-13272. [CrossRef]

84. Fan, X.; Liu, Y.; Tao, J.; Weng, Y. Soil Salinity Retrieval from Advanced Multi-Spectral Sensor with Partial Least Square Regression. Remote Sens. 2015, 7, 488-511. [CrossRef]

85. Pang, G.; Wang, T.; Liao, J.; Li, S. Quantitative Model Based on Field-Derived Spectral Characteristics to Estimate Soil Salinity in Minqin County, China. Soil Sci. Soc. Am. J. 2014, 78, 546-554. [CrossRef]

86. Yan, B.; Fang, N.F.; Zhang, P.C.; Shi, Z.H. Impacts of land use change on watershed streamflow and sediment yield: An assessment using hydrologic modelling and partial least squares regression. J. Hydrol. 2013, 484, 26-37. [CrossRef]

87. Janik, L.J.; Forrester, S.T.; Rawson, A. The prediction of soil chemical and physical properties from mid-infrared spectroscopy and combined partial least-squares regression and neural networks (PLS-NN) analysis. Chemom. Intell. Lab. Syst. 2009, 97, 179-188. [CrossRef]

88. Prasad, A.M.; Iverson, L.R.; Liaw, A. Newer classification and regression tree techniques: Bagging and random forests for ecological prediction. Ecosystems 2006, 9, 181-199. [CrossRef]

89. Li, Y.Y.; Zhao, K.; Ren, J.H.; Ding, Y.L.; Wu, L.L. Analysis of the Dielectric constant of saline-alkali soils and the effect on radar backscattering coefficient: A case study of soda alkaline saline soils in Western Jilin Province using RADARSAT-2 data. Sci. World J. 2014, 2014, 563015. [CrossRef] [PubMed]

90. Akiyama, T.; Kawamura, K. Grassland degradation in China: Methods of monitoring, management and restoration. Grassl. Sci. 2007, 53, 1-17. [CrossRef] 